
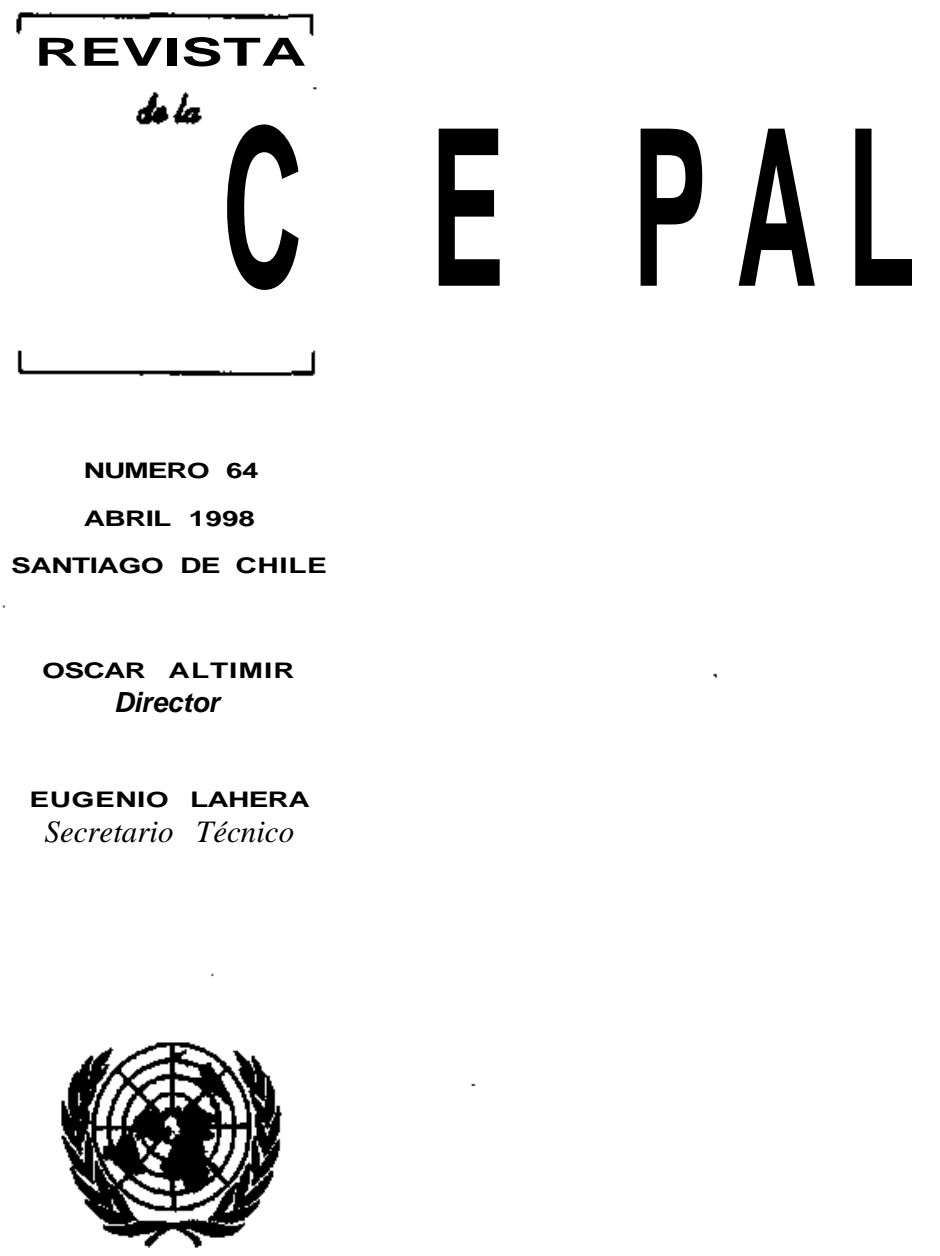

NACIONES UNIDAS 
Instituciones y crecimiento ¿Puede el capital humano ser un vínculo?

Nauro Campos y Jeffrey B. Nugent

Flujos de capital externo en América Latina y el Caribe en los años noventa: experiencias y políticas

Gunther Held y Raquel Szalachman

El Banco Central y la política macroeconómica de Chile en ios años noventa

Roberto Zahler

Política fiscal, ciclo y crecimiento

Ricardo Mariner

La convergencia hacia mejores prácticas productivas y de políticas: el acuerdo de la OMC sobre medidas de inversión vinculadas al comercio

Francisco Sercovich

Efectos para América Latina de la expansión de la Unión Europea

Peter Nunnenkamp

La dimensión Norte-Sur de las industrias de limpieza ambiental

y la difusión de tecnologías limpias

Jonathan R. Barton

La evolución del papel del Estado en la regulación del transporte terrestre

Ian Thomson

Manejo integrado del recurso agua, con la perspectiva de los

Principios de Dublin

Miguel Solanes

Publicaciones recientes de la CEPAL 


\section{La evolución del papel del Estado en la regulación del transporte terrestre}

\section{lan Thomson}

Unidad de Transporte,

División de Comercio

Internacional,

Transporte y

Financiamiento,

CEPAL.
Desde hace casi veinte años el sector transporte terrestre de varios países latinoamericanos ha experimentado cambios institucionales muy significativos, tanto con la participación del sector privado como con la flexibilización de la reglamentación económica, originando nuevas necesidades de regulación del mercado en general y de las entidades productoras en particular. Los cambios más importantes se dieron en el transporte ferroviario y autobusero, y en la infraestructura para el transporte carretero. Dentro de la región, tuvieron lugar primero en Chile y revirtieron el anterior predominio de la intervención estatal como parte de un modelo de desarrollo que había comenzado a agotarse, Tras los procesos de privatización, la empresa privada concesionaria de un ferrocarril o una carretera puede ejercer algunos poderes anticompetitivos, no sólo discriminando injustificadamente entre los usuarios de sus servicios sino también desincentivando la producción económica o desviando el transporte a otro medio de un costo real superior. Conviene entonces que los contratos de concesión restrinjan las posibilidades de que el concesionario aproveche dichos poderes en su propio beneficio y en contra de los intereses de la comunidad, y que a la vez mantengan los incentivos para que eleve su eficiencia. La desreglamentación de un mercado podría llevar a que un operador dominante, o un grupo de operadores, use su influencia o capacidad financiera para eliminar la competencia, lo que las leyes antimonopolios deberían poder impedir, Sin embargo, a veces éstas deben reforzarse, por ejemplo, con la facultad de aplicar a los infractores medidas punitivas o disuasivas. Además, en el transporte colectivo de ciudades grandes la desreglamentación puede conducir a costos sociales innecesarios, como externalidades relacionadas con la congestión o la contaminación atmosférica. En este caso, la licitación de las concesiones de explotación de los servicios podría ser la solución más indicada. Las concesiones de corta duración favorecen la competitividad del mercado, mientras que las más largas impulsan a los concesionarios a invertir en la actividad. Un sistema óptimo de concesiones podría involucrar el concepto de leasing de instalaciones fijas y de equipo rodante de larga vida. 
I

\section{El transporte terrestre en América Latina en los últimos veinte años}

\section{i. El sector privado toma las riendas en el trans- porte ferroviario}

Es notable el cambio ocurrido entre fines de los años setenta y fines de los noventa en el ambiente institucional del transporte terrestre latinoamericano, sobre todo en cuanto a la distribución de las operaciones entre los sectores público y privado. En el caso del transporte ferroviario (cuadro 1) es probable que a fines del siglo solamente en países como Paraguay, Uruguay y Venezuela, donde el transporte ferroviario es de poca importancia, seguirá siendo el sector estatal el que opere los trenes. En el resto de la región, las vías férreas continuarán siendo de propiedad del Estado, pero la operación ferroviaria estará en manos de concesionarios privados. En el mundo hay ya dos países donde todos los trenes de las redes principales corren por cuenta de empresas privadas, y uno de ellos es sudamericano: Bolivia. ${ }^{1}$ Incluso en países como Brasil, tradicionalmente inclinados a la intervención estatal en las operaciones de transporte, los ferrocarriles se concesionan.

Hace veinte años, lo típico era que en los países latinoamericanos existiera un ferrocarril fuertemente subvencionado, de propiedad estatal, cuyos objetivos empresariales no solían expresarse en términos muy explícitos y que eran interpretados de tal forma que premiaban el bienestar social a costo de las utilidades comerciales, con lo cual a veces la fijación de las tarifas ni siquiera tenía como finalidad aproximarlas al costo de operar el servicio.

A modo de ejemplo, los fletes de la empresa estatal Ferrocarriles Argentinos se definieron en función de la "capacidad contributiva de los usuarios" o "el valor de los bienes transportados" (Argentina, Ministerio de Economía y Obras y Servicios Públicos, 1977). El uso de tales criterios en la fijación de los fletes ferroviarios contribuyó en muchos países del mundo, incluidos algunos latinoamericanos, a las dificultades financieras y la pérdida de mercado de los ferrocarriles. En compensación, Ferrocarriles Argentinos fue

\footnotetext{
${ }^{1}$ El otro es Gran Bretaña.
}

CUADRO I

América Latina (11 países): Sector, público o privado, que opera el sistema ferroviario nacional, 1977 y 1997

\begin{tabular}{lll} 
& & \\
\hline Argentina & Sector" & \\
Bolivia & $\mathrm{F}$ & $\mathbf{p b}$ \\
Brasil & $\mathrm{F}$ & $P$ \\
Colombia & $\mathrm{F}$ & $P$ \\
Chile & $\mathrm{F}$ & $\mathrm{SM}^{\mathrm{C}}$ \\
Ecuador & $\mathrm{F}$ & $\mathrm{SM}^{\mathrm{e}}$ \\
México & $\mathrm{F}$ & $\mathrm{F}$ \\
Paraguay & $\mathrm{F}$ & $\mathrm{SM}^{\mathrm{C}}$ \\
Perú & $\mathrm{F}$ & $\mathrm{F}$ \\
Uruguay & $\mathrm{F}$ & $\mathrm{F}$ \\
Venezuela & $\mathrm{F}$ & $\mathrm{F}$ \\
\hline
\end{tabular}

Fuente: Elaboración propia, sobre la base de informaciones procedentes de diversos números de las publicaciones Riele.!', Realidad ferroviaria, International Railway Journal, Jane '.v World Railways, y de entrevistas con gerentes de empresas ferroviarias de los países de la región.

${ }^{a} \mathrm{~F}=$ operado por el gobierno federal o nacional. $\mathrm{P}=$ operado por empresas privadas. $\mathrm{SM}=$ sistema mixto.

b Una línea todavía por darse en concestón.

c Privatización anunciada o ya en camino.

favorecida con una serie de privilegios, como la exención del pago de los aranceles de importación y una subvención (que en 1977 ascendió a 210 millones de dólares), lo que habría desincentivado su administración eficiente.

\section{Nunca fue lógico estatizar el transporte camio- nero, y era muy complicado reglamentario}

El ferrocarril competía con un sector camionero que, en el ámbito económico, se encontraba efectivamente desreglamentado; ${ }^{2}$ sin embargo, a lo menos en el caso

\footnotetext{
${ }^{2}$ En el presente trabajo, se usa el término desreglamentación para referirse a la eliminación de todos (o la gran mayoría de) los controtes sobre las materias económicas relacionadas con la oferta de un servicio (tarifas, frecuencias, ingreso a la actividad, egreso, etc), En algunas instancias, se sugiere la regulación de un mercado desreglamentado, lo que significa básicamente su ordenamiento a través de una planificación del servicio, manteniendo elementos de competencia entre los operadores, los que determinarían las características económicas de sus servicios dentro de un marco regulatorio determinado por las autoridades.
} 
argentino, esta situación no se dio por convicción, sino por la dificultad de llevar la desreglamentación a la práctica (Argentina, Ministerio de Economía y Obras y Servicios Públicos, 1977, pp.46 y 171). La Ley $\mathrm{N}^{\circ} 12.346$ facultó la regulación y control sobre el transporte carretero de cargas, pero no fue factible aplicar los artículos correspondientes; en otros países hubo intentos de controlar los fletes camioneros, pero siempre resultó imposible.

Los casos de operación estatal del transporte camionero, en economías de mercado son sumamente raros. Por razones básicamente ideológicas, se formaron empresas camioneras estatales en el Reino Unido a fines de los años cuarenta, y en Bolivia a mediados de los ochenta, pero sin que hubiera justificación económica alguna, y sin que las empresas existentes estuviesen amenazadas de una insolvencia que aconsejara un rescate gubernamental.

Así, los cambios institucionales que han transformado el transporte terrestre en los últimos veinte años han tocado muy poco al sector camionero, que ya era operado privadamente y estaba bastante desreglamentado, excepto en lo que se refiere al transporte internacional.

\section{En el transporte urbano, también manos priva- das al volante}

En lo que hace a los autobuses urbanos en las capitales u otros centros importantes, entre 1977 y 1997 sólo en Quito se desafió la tendencia general a la sustitución de la operación pública por la privada. En el Distrito Federal de México, el servicio fue estatizado y luego devuelto al sector privado. Hace veinte años, en ciudades importantes como Arequipa, Brasilia, Río de Janeiro, São Paulo, Recife, Lima, Mendoza y Caracas, una parte importante de los servicios de autobuses era proporcionada por empresas de propiedad pública, normalmente municipales, pero a veces provinciales o nacionales.

\section{En el transporte autobusero interurbano nun- ca fue significativa la operación estatal}

Por otra parte, han sido pocos los casos de participación de empresas públicas en el transporte caminero no urbano de personas. Solamente en Cuba ha sido importante la operación estatal de esa categoría de transporte. Sin embargo, aunque el transporte autobusero interurbano no ha sufrido cambios de propiedad, en lo que se refiere a la reglamentación ha experimentado reajustes fundamentales en algunos países.
CUADRO 2

América Latina (algunas ciudades): Propiedad privada, municipal o federal/ nacional de empresas autobuseras, 1977 y $1997^{\mathrm{a}}$

\begin{tabular}{lccccc} 
& \multicolumn{2}{c}{1977} & & \multicolumn{2}{c}{1997} \\
\cline { 5 - 6 } Ciudad & Mayor & Menor & & Mayor & Menor \\
\hline Buenos Aires & $\mathrm{P}$ & - & $\mathrm{P}$ & - \\
La Paz & $\mathrm{P}$ & & $\mathrm{P}$ & - \\
Sāo Paulo & $\mathrm{P}$ & $\mathrm{M}$ & $\mathrm{P}$ & - \\
Santafé de & & & & \\
Bogotán & $\mathrm{P}$ & $\mathrm{F} / \mathrm{M}$ & $\mathrm{P}$ & - \\
Quito & $\mathrm{P}$ & - & $\mathrm{P}$ & $\mathbf{M}$ \\
México, D.F. & $\mathrm{P}$ & $\mathrm{F} / \mathrm{M}$ & $\mathrm{P}$ & $\mathrm{F} / \mathrm{M}^{\mathrm{b}}$ \\
Asunción & $\mathrm{P}$ & - & $\mathrm{P}$ & \\
Lima & $\mathrm{P}$ & $\mathrm{F}$ & $\mathrm{P}$ & - \\
Montevideo & $\mathrm{P}$ & - & $\mathrm{P}$ & - \\
Caracas & $\mathrm{P}$ & $\mathbf{M}$ & $\mathrm{P}$ & $\mathrm{F}$ \\
\hline
\end{tabular}

Fuente: Elaboración propia, sobre la base de infòrmaciones recopiladas de entrevistas con autoridades y empresarios y en distintos seminarios o encuentros organizados por la CEPAL, el Comité Técnico de los Congresos Latinoamericanos de Transporte Público y Urbano y entidades nacionales.

${ }^{a} \mathrm{P}=$ propiedad privada. $\mathrm{M}=$ propiedad municipal. $\mathrm{F}=$ propiedad federal o nacional.

En los casos de Santafé de Bogotá y del Distrito Federal de México, las empresas operadoras del sector público son distritales, pero el distrito corresponde al gobierno nacional.

$b$ Todas las empresas privatizadas al llegar a fines de año.

Vale aclarar que en 1977 los gobiernos sí participaban del transporte interurbano de pasajeros, por las vías férreas y aéreas. Muchas de las aerolíneas nacionales, tales como Aeroperú, Lan Chile, Lloyd Aéreo Boliviano, VASP, VIASA, etc, eran de propiedad de los gobiernos nacionales o provinciales; ahora están todas en manos privadas (sin considerar el caso de la empresa Iberia, perteneciente al gobierno español, que sigue manteniendo una participación en algunas); y los ferrocarriles estatales de casi todos los países de la región ofrecían servicios interurbanos para pasajeros. Pero en 1997, salvo en casos contados (sur de Chile, Cusco-Carillanca y la Provincia de Buenos Aires) esos trenes ya no corrían, o tenían escasa o nula significación. Los directores de los ferrocarriles privatizados han mostrado muy poco entusiasmo por operar trenes de pasajeros, salvo en el caso del Ferrocarril Oriental boliviano.

\section{Los gobiernos intervinieron en el transporte autobusero interurbano y urbano, mediante la regulación}

En 1977, las empresas privadas dedicadas al transporte de pasajeros, tanto urbano como interurbano, esta- 
ban sujetas a una fuerte reglamentación estatal; sus tarifas se aprobaban en los gabinetes ministeriales y la capacidad y/o frecuencias se controlaban. Sobre todo fuera de las áreas urbanas, las empresas básicamente asumían el papel de contratistas, o sea, de operadoras de servicios definidos por las autoridades, y tenían pocos incentivos para mejorar la calidad del transporte ofrecido o de desarrollar iniciativas en su comercialización. Un observador de esa época comentó que la reglamentación contemporánea impedía el ingreso de nuevos empresarios, inhibía la competencia, generaba pocos incentivos para mejorar el servicio y actuaba en contra del uso eficiente de los escasos recursos disponibles en el sector (González Narváez, 1992).

En algunos países - Brasil, por ejemplo-, la reglamentación aún sigue congelada en las condiciones de hace 20 años. Incluso en 1990, refiriéndose al transporte interurbano autobusero en el Brasil, la CEPAL observaba que "Por lo menos desde el año 1945, ninguna empresa había perdido su autorización" para operar una linca (CEPAL, 1991). Desde 1990, el gobierno brasileño ha propuesto la desreglamentación, pero ha encontrado siempre la férrea resistencia de las empresas monopólicas - normalmente sólo una por ruta $-\mathrm{y}$ hasta ahora ha tenido que ceder.

\section{La reglamentación tradicional y sus problemas}

Generalmente, las empresas de propiedad estatal se han autorregulado, de conformidad con las disposiciones sobre seguridad, condiciones técnicas, principios tarifarios, etc, inscritas en los artículos legislativos que las habían creado. A veces, esto las ponía en desventaja frente a las empresas privadas activas en el mismo sector, las que no estaban obligadas a cumplir con las mismas normas o que no las cumplían porque el control o fiscalización era demasiado relajado (Argentina, Ministerio de Economía y Obras y Servicios, 1972, p.176).

A las empresas autobuseras privadas se les aplicaba una serie de reglamentos dirigidos no solamente a materias técnicas o relacionadas con la seguridad, sino también al ámbito económico. Una preocupación implícita o explícita en dichos reglamentos era el temor de que las acciones naturales del mercado pudieran conducir a que algunos segmentos del mercado fuesen dejados desatendidos, o con servicios de una calidad inaceptable. Particularmente en el transporte de pasajeros, para tratar de asegurar el suministro de servicios adecuados los gobiernos licitaron concesiones u otorgaron permisos, que solían ser retenidos casi permanentemente por las mismas empresas. Luego, con el fin de proteger a los usuarios de los poderes monopólicos que de esa manera habían creado, las autoridades impusieron sobre las empresas operadoras una serie de reglamentos sobre tarifas, frecuencias, transferencia de vehículos a otros servicios, etc.

En el caso particular del transporte interurbano de pasajeros, la imposición de restricciones sobre el número de empresas operadoras o las frecuencias en las distintas rutas hizo que, en momentos de alta demanda, los factores de ocupación ascendieran a los máximos factibles y muchos pasajeros potenciales simplemente no pudieron adquirir pasajes, al menos sin recurrir al mercado negro (CEPAL, 1991).

Cuando diferentes niveles de gobierno imponían sus respectivas normas reglamentarias, se daban incongruencias entre las de unos y otros; por ejemplo, las tarifas cobradas por los servicios correspondientes al gobierno nacional y por los paralelos administrados por un gobierno regional a veces diferían entre sí. Los intentos de resolver tales incongruencias llevaron a aplicar medidas también incoherentes, como prohibir que los servicios de jurisdicción federal, durante sus recorridos por una provincia, pudiesen transportar a pasajeros desde un punto a otro dentro de esa provincia, aunque se detuvieran en ambos.

Se observa que hubo una tendencia a fijar tarifas relativamente bajas, especialmente en el transporte urbano, con el fin de reducir los gastos de movilización de los sectores de menores ingresos y/o limitar los índices de inflación (CEPAL, 1992). Junto con la incertidumbre legal que rodeaba a muchas de las operaciones, esto trajo consigo varias consecuencias desafortunadas: por ejemplo, merma de las tasas de renovación de las flotas y coeficientes excesivos de ocupación de los buses (Thomson, 1994). El resultado fue un servicio de tarifa baja y de calidad también baja. Además, la situación propiciaba la creación de un ambiente de deshonestidades entre las autoridades fiscalizadoras y las empresas privadas. En un caso a lo menos, en la ciudad de Río de Janeiro, algunas empresas hicieron llegar a las primeras datos falsificados acerca de los volúmenes de pasajeros transportados, con el fin de que se les autorizasen tarifas más altas.

En casos importantes, los subsidios se concedieron no solamente a empresas del sector público, fomentando su ineficiencia, sino también a las privadas, a veces llevando a fugas financieras por distintos aprovechamientos de la situación para fines propios (CEPAL, 1992). Un análisis referente a los países desarrollados concluyó que cada dólar, o su equivalente, destinado a la subvención del transporte colectivo urbano, bene- 
ficiaba a los usuarios sólo en 60 centavos; alrededor de 40 centavos del subsidio se perdía a través de sueldos más altos, la ocupación de un número excesivo de empleados, etc. (Bly, Webster y Pounds, 1980). A mediados de los años ochenta, el déficit anual de las empresas públicas de transporte colectivo en México y São Paulo ascendía a más de 150 millones de dólares, en cada caso (CEPAL, 1992).

\section{Una situación que reclamaba reformas}

La situación institucional del transporte terrestre había llegado a una etapa en que era oportuno un cambio fundamental, que ya se ha dado (o ha comenzado a darse) en países como Argentina, Bolivia, Chile, México y Perú. En otros las reformas están aún por llegar, atrasadas a veces debido a las trabas que imponen los inte- reses favorecidos por las reglamentaciones, como las empresas de buses que operan líneas cuyas concesiones nunca parecen abrirse a la competencia. En los países desarrollados, la reglamentación del transporte terrestre no era radicalmente diferente a la de América Latina, pero funcionaba mejor porque los mercados exhibían una relativa estabilidad, la burocracia era más eficiente $\mathrm{y}$, además, en lo referente al transporte de pasajeros, porque era menor la importancia del transporte público frente al privado.

La reforma surgió en diferentes países, con mucha independencia entre un caso y otro. Entre los países desarrollados, destacan las innovaciones en los Estados Unidos y Gran Bretaña. Además, en Nueva Zelandia se hicieron cambios interesantes. En América Latina, Chile ocupó una posición de vanguardia. De todas estas experiencias hay mucho que aprender.

\section{II}

\section{El ascenso y descenso de la intervención estatal}

\section{La intervención estatal creciente}

Mucho antes de la segunda guerra mundial, y con escasas excepciones, en el mundo entero se tendió a una creciente participación del Estado en el sector transportes, como operador o como reglamentador de las actividades de las empresas del sector. La participación del Estado como operador fue motivada inicialmente, en la mayoría de los casos, por la insolvencia de las empresas ferroviarias, tranviarias y otras, a raíz de factores como: i) los cambios tecnológicos en el transporte automotor y las carreteras; ii) el aumento de los ingresos (que fomentó la adquisición de vehículos particulares y redujo la demanda de medios colectivos), y iii) la dispersión en el uso del suelo (que restó competitividad a los medios tradicionales, obligados a transitar por vías fijas). Además, en algunos países, como Argentina o el Reino Unido, fue la ideología política la que condujo a la operación estatal.

Normalmente, la reglamentación estatal antecede a la operación por parte del Estado, empezando, en el caso del transporte terrestre mecanizado, con los ferrocarriles y los tranvías. En el caso de las empresas de tranvías estaba clara la necesidad de regulación en el área de la seguridad, por su uso compartido de las vías públicas con otros vehículos y con los peatones. Sin embargo, ya en el siglo pasado algunas autoridades municipales, preocupadas por la posición monopólica de las empresas - como las de Bogotá o Buenos Aires-impusieron sobre éstas un control tarifario o distintas medidas destinadas a garantizar la calidad del servicio a los usuarios (Jaramillo y Parías, 1995; Scobie, 1977). En años posteriores, el control tarifario demasiado rígido contribuyó muy significativamente a la estatización o municipalización de las empresas de tranvías (CEPAL, 1994).

\section{La reglamentación llegó temprano a los ferro- carriles}

La llegada de los ferrocarriles mejoró de manera muy importante la accesibilidad de las personas a los lugares donde quisieran ir y redujo considerablemente los costos del transporte de bienes. Aunque las empresas ferroviarias cobraban tarifas monopólicas, los precios del transporte ferroviario todavía eran inferiores a los que regían antes, de modo que en los primeros días la regulación no se orientó hacia las materias económi- 
cas. Luego se empezó a olvidar cómo era el mundo antes del arribo de las empresas ferroviarias y a tomar conciencia de que a veces éstas actuaban de manera monopólica o discriminatoria, lo que motivó la aplicación de una reglamentación económica. Esto ocurrió a nivel nacional en los Estados Unidos en 1887, con el establecimiento de la Comisión interestatal de comercio, cuyos poderes se ampliaron en 1935 al transporte carretero de pasajeros y de carga; esta ampliación se debió en parte a la influencia de las empresas ferroviarias, que presionaron para que el transporte camionero no tuviera mayores libertades comerciales que ellas. En el Reino Unido, el Parlamento comenzó a interesarse en la reglamentación de los ferrocarriles mucho antes, en 1835, y al llegar a 1914 éstos probablemente eran la actividad económica más reglamentada en ese país (Dyos y Alderoft, 1969).

\section{Como se desreglamentó en los Estados Uni- dos}

Sólo en el último cuarto del siglo XX se hizo un intento serio de desreglamentar el sector transporte en los Estados Unidos, a través de leyes como la Ley de revigorización y reforma regulatoria de los ferrocarriles (en 1976), que flexibilizó la fijación de fletes, y la Ley de desreglamentación aérea (en 1978), que puso en marcha un programa de liberalización de las tarifas y del ingreso a la actividad. Luego, en 1980, la conocida Ley de Staggers concedió mayor libertad de acción a las empresas ferroviarias y la Ley de reforma de los transportadores motorizados flexibilizó algo la fijación de tarifas y el ingreso a la actividad en el transporte carretero de carga. Cuatro años después se aprobó la Ley de reforma regulatoria autobusera, que hizo lo mismo en el caso del transporte interurbano por buses \{Transportation Quarterly, 1985).

Button (1990) clasifica la reglamentación estadounidense en tres categorías: i) la económica (sobre tarifas, niveles de producción, número de productores, etc); ii) la social (sobre seguridad, protección del consumidor, etc), y iii) la antimonopolios. Considera que la desregulación ha estado relacionada formalmente sólo con la primera de estas categorías, aunque también ha habido algunas reinterpretaciones de la tercera que han desembocado en una desreglamentación parcial de hecho. (Cabe observar que el sistema de clasificación de Button es algo inusual, y, de hecho, cada una de las tres categorías comprende materias frecuentemente consideradas como pertenecientes al dominio de la economía).
Los argumentos de los economistas que cuantificaron el alto costo de la reglamentación constituyeron una motivación importante a favor de la desregulación. En algunos casos, pudieron comparar una actividad desreglamentada — por ejemplo, la aviación comercial en algunos estados grandes- con otra donde regía la reglamentación. Además, hubo sugerencias de que la regulación tendía a beneficiar a las empresas ya establecidas o a los propios reguladores (Button, 1990). La teoría de los mercados potencialmente abiertos (contestable markets) enseñó que el libre acceso a un mercado pudo hacer que un oferente dominante actuara como si realmente tuviera que enfrentar competencia, aunque ésta fuera potencial más que real. ${ }^{3}$ Otro factor que fomentó una consideración cada vez más seria de la posibilidad de desreglamentar fue un menor dinamismo en la economía, y las sugerencias de que el crecimiento se vería impulsado por una economía en que existieran mayores incentivos. Los proponentes de la desregulación pudieron afirmar que los casos anteriores en que se había desreglamentado (por ejemplo, el del transporte camionero británico y el de diferentes subsectores en algunos estados estadounidenses) habían sido generalmente exitosos.

\section{La desreglamentación y privatización británi- cas}

En el Reino Unido, la desreglamentación en el sector transporte tomó más tiempo que en los Estados Unidos, aunque hubo una concentración marcada de actividades en el área bajo el gobierno conservador, entre 1980 y 1996. En Gran Bretaña, el proceso involucró también la desestatización de los servicios de buses urbanos e interurbanos y del sistema ferroviario (además de los puertos y la aviación comercial). En los Estados Unidos, el sistema ferroviario nunca estuvo en manos estatales (salvo, transitoriamente, durante el rescate del Penn Central); tampoco los buses interurbanos; los urbanos siguen perteneciendo en muchos casos al sector gubernamental.

El transporte camionero británico se había dejado bastante desreglamentado en 1968, por un gobierno socialista; sin embargo, el primer paso definitivo hacia una desreglamentación general sólo se dio en

\footnotetext{
${ }^{3}$ Button menciona que una consecuencia de la desregulación de la aviación civil fue la reducción de las tarifas en rutas principales, y el alza en rutas de menor volumen sin competencia. Es decir, en la práctica, la vigencia total de la teoría de los mercados potencialmente abiertos permanece, en algunas instancias, por verificarse.
} 
1980, con la aprobación de una ley que liberalizó el transporte autobusero no urbano y promovió la privatización de las empresas operadoras públicas que participaban en el área. A mediados del mismo decenio se aplicaron medidas comparables en el transporte autobusero urbano no londinense. En Londres, se privatizaron las empresas de buses pero, más que liberalizar la oferta, se introdujo un esquema regulado que incluía la licitación de los recorridos. ${ }^{4}$ En lo que al transporte terrestre se refiere, el proceso se completó con la privatización de los ferrocarriles entre 1994 y 1997.

El gobierno laborista que asumió el control político en este último año no ha mostrado interés en volver a estatizar los ferrocarriles, aunque sí pretende reforzar la regulación de las empresas, o usar la amenaza de una mayor regulación como mecanismo para fomentar una mayor preocupación por la calidad del servicio ofrecido al público o el aumento de las inversiones (recuadro 1). Tampoco piensa reestatizar el sector autobusero, pero sí regular los servicios operados.

Recuadro 1

LA POSIBILIDAD DE MÁS REGULACIÓN COMO ESTÍMULO AL COMPORTAMIENTO COMPETITIVO DE EMPRESAS EXISTENTES EN MERCADOS MONOPÓLICAS

La teoría de los mercados potencialmente abiertos se desarrolló y se aplica en el contexto del posible ingreso de nuevos competidores como estimulo al comportamiento competitivo de las empresas existentes que ejercen poderes monopolísticos. Sin embargo, el mismo comportamiento puede inducirse por la amenaza de una mayor regulación. Los casos de ese tipo de reacción incluirían la política tarifaria del North Eastern Railway inglés en el siglo pasado, una rebaja de tarifas (tras un alza que el Ministro del sector consideró injustificada) declarada por la agrupación de autobuseros urbanos de Santiago de Chile a principios de los años noventa, y los planes de inversión de algunas de las empresas ferroviarias británicas recientemente privatizadas, al asumir un gobierno laborista a mediados de 1997.

\footnotetext{
${ }^{4}$ Inicialmente, se pretendió desreglamentar también en Londres. Luego, hubo un intercambio de opiniones e informes sobre la materia entre el Presidente del Directorio de la empresa estatal London Transport y la Unidad de Transporte de la CEPAL, que recomendó no desreglamentar en ciudades grandes, como Londres. No sabemos hasta qué punto influyeron las recomendaciones de la CEPAI. en el cambio de política.
}

\section{En otros países desarrollados no pasa mucho}

Se observa en otros países europeos una cierta incomprensión de la lógica inherente a la desreglamentación y las privatizaciones británicas, a pesar de que ellas parecen haber sido generalmente exitosas. En la Europa continental se da mayor importancia a materias como la integración de la red de transportes, y se estima que los objetivos globales del Estado en el área del transporte se pueden lograr más eficazmente si el propio Estado opera el sistema. En cuanto a los puertos, mientras en el Reino Unido se adopta el balance financiero como marco de análisis, al otro lado del Canal de la Mancha la contribución al desarrollo de las zonas en que ellos están ubicados recibe una mayor atención. En los países europeos continentales, los cambios que sí han ocurrido provienen principalmente de decisiones tomadas arriba, es decir, a nivel de la Unión Europea más que a nivel de los gobiernos de cada país. La experiencia angloestadounidense se comenta mucho, pero ha orientado poco las políticas de otros países desarrollados.

Una excepción destacada es la también anglosajona Nueva Zelandia, donde el proceso privatizador y desreglamentador muestra mucha similitud con el caso británico. Hasta las mismas empresas privadas han adquirido concesiones en ambos países: por ejemplo, la estadounidense Wisconsin Central en el transporte ferroviario de carga y la británica Stagecoach en el ámbito de los buses urbanos.

\section{En América Latina, la desreglamentación co- menzó en Chile}

A mediados de los años setenta, en Chile se efectuó una reforma fundamental de la economía, que comprendió una liberalización bastante completa de las actividades económicas, incluida la de transporte. El transporte camionero se desreglamentó primero, en 1975, mediante la aplicación de una ley antimonopólica. (El gobierno anterior había controlado tanto la importación de camiones, concediendo un virtual monopolio a una marca española, como el ingreso a la actividad y el valor de los fletes.) Luego, entre 1977 y 1979, se liberalizó el ingreso, el egreso y las tarifas del transporte autobusero interurbano. Después, mediante un proceso que solamente se completó en 1987, se hizo lo mismo en el ámbito urbano (CEPAL, 1987).

Los promotores de esa desreglamentación chilena no fueron, en general, los técnicos o profesionales en el área de los transportes, sino los economistas gene- 
rales seguidores de la escuela de Chicago, quienes suelen considerar indiscriminadamente muchos sectores de la economía. En una ocasión, el Ministro de Transportes y Telecomunicaciones, un general de la Fuerza Aérea de Chile, trató de mantener elementos de control cuantitativo sobre la flota de buses que operaba en Santiago, pero prevaleció la opinión contraria del Ministro de Hacienda, un ingeniero de ideas económicas neoliberales del modelo de Chicago (Thomson, 1992).

Cabe mencionar que, como parte de la desreglamentación en Chile, se hicieron intentos serios de maximizar la eficiencia del mercado, por ejemplo, a través de distintas medidas orientadas a brindar a los usuarios de los buses la información necesaria para elegir racionalmente entre los diferentes servicios ofrecidos, a defender los derechos de los usuarios, y a promover una conducta responsable de las empresas operadoras (a través del cobro de multas altas por extravío de equipaje en buses interurbanos, la consideración del pasaje como un contrato legal entre el transportador y el pasajero, etc).

La experiencia chilena de desreglamentación del transporte fue bastante criticada en otros países de la región, con razón en algunos casos y sin ella en otros. (El hecho de que las reformas fueran introducidas bajo un gobierno militar seguramente habrá contribuido a la cantidad de voces en contra). En el transporte de carga, las reformas chilenas no dieron por resultado una institucionalidad muy diferente a la de otros países de la región; sin embargo, en el transporte interurbano de pasajeros, durante varios años ni la política adoptada por Chile ni la situación resultante tuvieron contraparte en algún otro país de la región. Aunque criticado en el extranjero, especialmente por los empresarios de países donde todavía les beneficiaba una legislación reglamentadora, cabe poca duda de que la nueva política chilena fue en general exitosa, llevando a servicios muy competitivos y eficientes. Las empresas operan de manera rentable y los usuarios pueden elegir entre calidades diferentes de servicios, cuyo nivel general es muy bueno, a tarifas también fluctuantes y en general inferiores a las cobradas en otros países analizados por la CEPAL a principios del presente decenio (CEPAL, 1991).

Además, en casi todas las ciudades chilenas se puede considerar exitosa la desreglamentación, aunque en los mayores centros urbanos, especialmente en Santiago, provocó una serie de problemas relacionados con el valor de las tarifas, la congestión y la contaminación del aire. Por el lado positivo, la cobertura del servicio ha mejorado notablemente. Las razones del me- nor éxito de la desreglamentación en ciudades grandes han sido evaluadas por la CEPAL en otras oportunidades (por ejemplo, véase Thomson, 1993). Aunque en los años noventa el gobierno del país ha implantado en Santiago una reglamentación bastante diferente de la de quince años antes, es significativo que no se hayan introducido modificaciones importantes en la institucionalidad económica del transporte colectivo interurbano o en el urbano de otras ciudades.

\section{La desreglamentación atraviesa fronteras, pero pocas}

El único otro país que ha adoptado un esquema de desreglamentación tan completo como el chileno es el Perú, donde en la práctica las medidas tuvieron un alcance aún mayor, pues se autorizó la importación de vehículos usados, muchos de los cuales, traídos desde países asiáticos, fueron adquiridos por pequeños empresarios y puestos en servicio en Lima u otras ciudades. Por lo demás, el uso para el transporte colectivo de vehículos de un tamaño intermedio entre un automóvil y un bus pequeño, que quedó prohibido en Chile, no tiene restricciones similares en el Perú, donde se han multiplicado los vehículos conocidos como Combi (por el furgón para personas de la marca Volkswagen).

El Decreto Legislativo $\mathrm{N}^{\circ} 640$, del 25 de junio de 1991, que eliminó "todos los obstáculos administrativos y legales que impidiesen el libre acceso de nuevos concesionarios ..." fue aplicado al transporte interurbano, donde en algunas rutas la inadecuada fiscalización de la condición mecánica de las unidades o las deficiencias de las regulaciones de seguridad condujeron, en 1997, a la decisión de congelar transitoriamente el parque de vehículos. Posteriormente, durante el mismo año un proyecto de Decreto Supremo, entre sus considerandos, señala que "el servicio público de transporte terrestre interprovincial de pasajeros por carretera en ómnibus se encuentra en estado de emergencia", por los altos índices de accidentes y otros factores (CIDATT, 1997). El nuevo proyecto propone el restablecimiento de un sistema de concesiones.

En Lima, las municipalidades otorgan concesiones para operar recorridos de transporte colectivo, pero sin tener el propósito de limitar el parque de vehículos. De todos modos, muchas unidades operan sin concesiones. Se considera que en Lima Metropolitana, a mediados de 1997, funcionaban alrededor de 55000 vehículos de transporte colectivo. Ya hay mucho interés a nivel metropolitano y municipal en la posibilidad de reordenar y racionalizar la red de rutas de transporte colectivo. 
En Argentina, en 1992, se desreglamentó el transporte automotor interprovincial de pasajeros, con resultados que no fueron evaluados de una manera general hasta fines de 1997. Las empresas operadoras se quejan de baja rentabilidad, pero los usuarios podrían estar satisfechos con la nueva situación. Como suele ocurrir cuando se desreglamenta un servicio de transporte autobusero, la oferta ha aumentado más que la demanda y los coeficientes de ocupación han bajado (cuadro 3). Siempre que la situación asì creada no sea de desequilibrio, seguramente será preferida por los usuarios a la anterior.

La situación sólo podrá perdurar si los costos de explotación se hubiesen reducido a partir de la puesta en marcha de la reglamentación, permitiendo a las empresas obtener utilidades adecuadas a tasas de ocu-

CUADRO 3

Argentina: Algunos indicadores del transporte autobusero de pasajeros interurbanos antes y después de la desreglamentación del servicio, 1990-1995

\begin{tabular}{lcccc}
\hline Año & $\begin{array}{c}\text { Número } \\
\text { de } \\
\text { empresas }\end{array}$ & $\begin{array}{c}\text { Buses } \\
\text { en } \\
\text { servicio }\end{array}$ & $\begin{array}{c}\text { Antigüedad } \\
\text { media del } \\
\text { parque }\end{array}$ & $\begin{array}{c}\text { Coeficiente de } \\
\text { ocupación }\end{array}$ \\
\hline 1990 & 152 & 2597 & 5.8 & S/i \\
1991 & 158 & 2597 & 5,6 & 0.70 \\
1992 & 160 & 2844 & 5.3 & 0.62 \\
1993 & 164 & 2934 & 5.1 & 0.54 \\
1994 & 165 & 3278 & 4.4 & 0,50 \\
1995 & 171 & 3695 & 4.2 & 0.38 \\
\hline
\end{tabular}

Fuente: Compendio estadístico del transporte en la Argentina. Secretaría de Obras Públicas y Transporte, Buenos Aires, 1996.

a El número de empresas no pudo aumentar, salvo marginalmente, por una característica del tipo de desreglamentación adoptado. pación inferiores a las de antes, o si las utilidades anteriores hubiesen sido excesivas. En Argentina, el transporte colectivo urbano, de jurisdicción tanto federal como provincial y municipal, sigue sin cambios importantes en cuanto a reglamentación.

En Bolivia, el transporte interurbano de pasajeros por buses se desreglamentó y hubo una significativa flexibilización reglamentaria en el ámbito urbano. Sin embargo, en América Latina, como en Europa, los casos de desreglamentación todavía constituyen excepciones a la norma general. Los chilenos se llaman a sí mismos los ingleses de América Latina; en lo que toca a la desreglamentación del transporte en Chile y Gran Bretaña, y al relativo escepticismo que ha despertado en muchos otros países latinoamericanos y en Europa continental, quizás tengan razón.

\section{La privatización marcha más rápido que la desreglamentación}

En la privatización de los servicios de transporte el avance en muchos países de América Latina ha sido más notable. A! término del siglo $\mathrm{XX}$, los únicos sistemas ferroviarios nacionales de la región que permanecerían en manos estatales serian los de países donde ese medio tiene poca importancia, como Paraguay y Venezuela (sin contar el caso peculiar de Cuba). Los únicos buses urbanos o interurbanos que seguirían siendo de propiedad pública serían los de algunas ciudades brasileñas, algunos trolebuses en Argentina y Ecuador, el Metrobus de Caracas, y algunos buses municipales en Quito (también sin tomar en cuenta el inusual caso cubano).

\section{III}

\section{La regulación económica del transporte en la situación actual}

Hoy nos encontramos cada vez más ante empresas privadas surgidas de la venta o concesión de empresas públicas que antes controlaban un mercado de transporte (caso A) y ante subsectores de! área del transporte en que la reglamentación anteriormente impuesta sobre las operadoras privadas ha sido eliminada, o es considerada restrictiva y está a punto de ser reformada (caso B). El problema de regulación no es idéntico en uno y otro caso.

\section{El caso A}

a) Las empresas con algunos poderes monopólicas En el caso A la empresa privada que se forma suele ubicarse en un mercado sobre el cual ejerce algunos poderes monopólicos. Conviene entonces disponer de instrumentos legales específicos para garantizar que no explote esos poderes en su propio beneficio y en contra de los intereses de la comunidad. La manipula- 
ción de sus propios fletes podría hacer que una empresa ferroviaria internalizara para sí misma una proporción demasiado alta de los excedentes de sus clientes cautivos. Lo mismo puede suceder en el caso de una carretera cuya administración se concesiona a una empresa privada, a la cual se le permite el cobro de peajes.

Salvo en casos excepcionales, el poder monopólico de la empresa transportista está lejos de ser total, por la existencia de opciones de transporte menos atractivos para el cliente (por ejemplo, los camiones, que se presentan como una alternativa a los trenes, o las rutas alternativas a una carretera concesionada). Sin embargo, aunque los camiones puedan transportar también productos voluminosos, como los minerales, lo harían a costos superiores; y las rutas alternativas pocas veces constituyen opciones convenientes.

Quizás el Estado no siempre tenga que preocuparse demasiado por la distribución de las utilidades entre, por ejemplo, una empresa ferroviaria y otra minera. ${ }^{5}$ Sin embargo, el cobro de altos fletes podría perjudicar el progreso económico, y no limitarse a influir en la distribución de los frutos de ese progreso entre las partes. Por ejemplo, el cobro de fletes muy superiores a los costos marginales podría desincentivar la inversión en nuevas minas, que sí se haría si los fletes ofrecidos fuesen más modestos.

La empresa monopolista, ferroviaria en el caso de nuestro ejemplo, podría cobrar fletes inferiores a los clientes nuevos, lo que provocaría acusaciones de tratamiento discriminatorio, además de desincentivar nuevas inversiones por parte del cliente tradicional.

Este último podría resolver su problema obteniendo del gobierno la concesión para operar el ferrocarril, en la licitación correspondiente, o posteriormente de quien se la adjudicara. Si lo hiciera, rebajaría los fletes que se cobraría a sí mismo, y los subiría para sus competidores, con resultados opuestos a los de la situación descrita en el párrafo anterior.

De todos modos, el cobro de altos fletes, que maximizaría los ingresos de la empresa ferroviaria, podría desviar una parte del tráfico a las carreteras, con un costo social que podría ser considerable por i) aumentos en los accidentes de tránsito, ii) destrucción de pavimentos debido a los altos tonelajes por eje de los ca-

\footnotetext{
${ }^{5}$ Vale señalar que un cliente minero puede depender de una empresa ferroviaria para el transporte de sus productos, o viceversa si el tráfico minero es de importancia primordial para el ferrocarril. Un ejemplo interesante de esto es el del complejo minero CentroMin, en la sierra central peruana, y el Ferrocarril Central; ambos son empresas estatales en vías de ser privatizadas.
}

miones, y iii) demoras causadas a los ocupantes de vehículos livianos atrapados detrás de camiones lentos en los caminos que atienden los pueblos mineros.

\section{b) La regulación de las empresas con algunos po- deres monopólicas}

En algunos casos, convendría que los gobiernos mantuviesen algún derecho a intervenir en los fletes cobrados, quizás garantizando que mantengan alguna relación razonable con los costos marginales correspondientes, para asegurar un tratamiento no discriminatorio entre clientes y para mantener la rentabilidad de la empresa ferroviaria dentro de límites razonables.

En el caso A, los reglamentos legales generales, antimonopólicos y otros no son suficientes, entre otras razones, por la naturaleza confidencial de los contratos comerciales (un cliente no podrá saber cuánto se le está cobrando al otro). En los contratos de concesión es necesario asegurar que la empresa monopolista no aproveche esta condición y que a la vez siga teniendo incentivos para mejorar la calidad de sus servicios y reducir sus costos.

En los Estados Unidos, el problema se resuelve, esencialmente, definiendo una tasa de rentabilidad razonable para la empresa monopolista. En el Reino Unido, el principio preferido es el de fijar la escala de tarifas que la empresa está autorizada a cobrar por un período de cinco años, expresada en un número de puntos porcentuales inferior o superior al índice de precios al consumidor (Powell, 1992). Las dos opciones tienen sus ventajas y desventajas. La estadounidense permite asegurar el interés de los inversionistas y mantener la rentabilidad aunque haya fluctuaciones inesperadas en el costo de los insumos, pero si la rentabilidad permitida se fija en un valor un poco superior al de mercado, podría incentivar a las empresas a hacer inversiones innecesarias, meramente para maximizar la rentabilidad de su capital, Bajo la opción británica, las empresas tendrían mayores incentivos para reducir sus costos, pero a veces no es fácil definir los reajustes autorizados en sus tarifas.

\section{c) La privatización ferroviaria británica: el papel de las empresas de leasing}

En el caso particular de los ferrocarriles británicos, el sistema de privatización separa la administración de la infraestructura ferroviaria y la operación de los trenes. Una empresa naturalmente monopólica, llamada Railtrack, administra las vías, y más de 20 otras empresas operan los trenes, en sectores diferentes de la red. El regulador de los ferrocarriles (Rail Regulator) 
requiere que Railtrack reduzca sus cobros en $2 \%$ real por año, tomando en cuenta las economías posibles en los costos de mantenimiento. La variación en las tarifas de pasajeros que cobran las empresas operadoras con poderes monopólicos, especialmente las que ofrecen servicios urbanos o suburbanos, también está sujeta a valores reales máximos (Glover, 1996).

La privatización ferroviaria británica contempla distintos mecanismos para asegurar un nivel adecuado de competitividad e incentivos para la operación de servicios de una calidad satisfactoria. Por ejemplo, las concesiones de los servicios de pasajeros duran entre siete y quince años; al final del período, habrá una relicitación. Algunas empresas operadoras están negociando para obtener que se extienda el período de su concesión, a cambio de realizar inversiones adicionales a las contratadas. Es una característica de la privatización ferroviaria británica que las empresas operadoras no están obligadas a adquirir sus propios equipos; inicialmente, todo el material rodante estuvo en manos de empresas de leasing, que también se han privatizado. Existe además la opción de adquirir equipo nuevo a través de alguna de las empresas de leasing, de las cuales hay tres. Algunos operadores prefieren adquirir sus equipos nuevos mediante tales empresas, mientras otros compran directamente, o a través de sus casas matrices.

\section{El caso B}

a) Los problemas de un mercado desreglamentado En el caso B el monopolio potencial podría ser también un problema. Por ejemplo, en el transporte interurbano de pasajeros, una empresa ya predominante podría tratar de liquidar a otras con menor capacidad financiera, cobrando tarifas muy reducidas hasta hacerlas retirarse del mercado. Situaciones de ese tipo se han dado en Chile, en el mercado del transporte autobusero y en la aviación comercial, y han llegado a las tribunales. En el plano internacional, acciones semejantes de la Pan American y la British Airways efectivamente eliminaron la amenaza comercial presentada por la incipiente aerolínea Laker.

Las empresas grandes podrían defenderse contra la competencia también de otras maneras: por ejemplo, construyendo un terminal propio y abandonando el terminal usado por las demás empresas, o haciendo que sus servicios corran siempre unos pocos minutos antes que los demás. (También ha habido ocasiones en que los parabrisas o neumáticos de los vehículos de nuevos competidores han aparecido misteriosamente rotos).
En varios casos podría darse una unión monopólica en virtud de acuerdos entre empresas operadoras destinados a controlar las tarifas o restringir la oferta. Normalmente tales acuerdos no toman la forma de documentos escritos y es difícil comprobar su existencia. Sin embargo, es casi seguro que en Santiago de Chile durante los años ochenta y en Lima diez años después, las entidades operadoras del transporte colectivo llegaron a entendimientos para el alza coordinada de las tarifas.

Especialmente respecto al transporte colectivo urbano, la desreglamentación también podría crear sobreoferta, al incentivarse excesivamente el ingreso de nuevas operadoras por el no pago de los costos marginales sociales que provocan. ${ }^{6}$ Dichos costos se relacionan con la congestión de tránsito, la contaminación del aire y los accidentes. Algo similar puede suceder en el transporte camionero: los impuestos que se le cobran normalmente no cubren los costos viales correspondientes, en el caso de los vehículos de mayor peso por eje.

El mercado del caso B permanecería al parecer potencialmente abierto, por la falta de barreras evidentes al ingreso de nuevas operadoras. Sin embargo, una barrera latente - como la amenaza de una guerra de precios o algo por el estilo- podría desalentar efectivamente el ingreso de nuevas empresas.

En el caso A el transportista puede discriminar entre diferentes grupos de clientes, pero esta opción no suele estar al alcance de las empresas en el caso B.

\section{b) Poniendo orden en un mercado desreglamentado, sin volver al pasado}

Cabe poca duda de que la reglamentación de antaño aminoró la motivación comercial de las empresas. El problema que deberá enfrentarse ahora en el transporte es cómo regularlo de manera que garantice la competitividad del mercado y beneficios sociales que superen los costos sociales causados, todo ello sin estrangular la mayor eficiencia que la privatización y la desreglamentación están destinadas a generar y permitiendo que las empresas privadas usen toda su capacidad de iniciativa para desarrollar mercados y reducir costos.

\footnotetext{
${ }^{6}$ La palabra "sobreoferta" se osa mucho y se define poco. Para la CEPAL, en referencia a los mercados desreglamentados, es la oferta que se produciría en casos en que los operadores no tuviesen que pagar la totalidad de los costos sociales marginales atribuibles a sus acciones.
} 
En los mercados desreglamentados, según ya se ha dicho, una empresa grande podría intentar dominar el mercado, y las operadoras podrían unirse, formal o informalmente, con ese mismo propósito. Las leyes antimonopolios pueden limitar tales tendencias, aunque a veces es difícil comprobar la existencia de acciones monopólicas, especialmente si no hay testimonios escritos o grabados de la aparente actuación coordinada de las empresas operadoras. ${ }^{7}$ Ante una empresa dominante que trata de liquidar a otras menores que participan en el mismo mercado, estas últimas podrían ganar en un juicio, pero solamente después de haber sido liquidadas (como sucedió con la aerolínea Laker). Una manera de resolver parcialmente problemas de este tipo es obligar a la empresa mayor a pagar una indemnización superior a los daños sufridos por las liquidadas, como se hace en los Estados Unidos.

Suele suceder que una empresa funcione transitoriamente a pérdida a fin de liquidar al competidor, entre otras cosas, reduciendo las tarifas a valores inferiores a los costos y operando servicios que partan pocos minutos antes que los de la empresa rival para quitarle pasajeros; y que una vez liquidada la competencia, suba las tarifas, a veces a valores bastante superiores a los costos. Una manera de desalentar tales prácticas es exigir que cada cambio de tarifa, de itinerario o de frecuencia se anuncie anticipadamente. Esto significaría, al menos, que la empresa liquidadora tendría que seguir ofreciendo sus rebajas especiales durante un período posterior al retiro de sus competidores, En Gran Bretaña, las empresas de buses tienen la obligación de informar a la autoridad de las modificaciones en sus servicios a lo menos 42 días antes de aplicarlas; esto se exige para que la autoridad tenga tiempo de licitar (con subsidio) servicios socialmente útiles que el mercado deje de suministrar, y también de producir itinerarios de los servicios, pero serviría también para reducir la incidencia de un comportamiento depredador.

Según ya se ha señalado, en Santiago de Chile la desreglamentación económica casi total en el transporte colectivo llegó a su fin a principios de los años noven- ta. El Ministerio de Transportes y Telecomunicaciones decidió identificar los servicios que convendría operar, y licitó su operación entre empresas del sector privado, constituidas normalmente sobre la base de los integrantes de las asociaciones de propietarios que anteriormente habían proporcionado los servicios. En general, la experiencia santiaguina ha sido bastante exitosa (Thomson, 1995).

En la capital chilena, la duración máxima de las concesiones es de siete años, al final de los cuales cada recorrido se relicita. Si el plazo fuera superior, las empresas podrían construir sus propias instalaciones para el mantenimiento de las unidades, pero se debilitaría la competitividad del mercado y las empresas tendrían menores incentivos para ofrecer una buena calidad de atención a sus clientes. Es probable que, de contar tales empresas con talleres propios, el mantenimiento de los buses sería mejor que si recurrieran a talleres comerciales, sobre todo si cada propietario contrata individualmente con ellos los servicios de mantenimiento de su unidad o unidades.

Una vía de salida del debate sobre las bondades de plazos cortos o largos para las concesiones podría ser la creación de empresas de leasing de talleres, que los arrendarían a las empresas asignatarias de las concesiones. Por lo que sabemos, esto no se hace en parte alguna; el caso del leasing del material rodante ferroviario en Gran Bretaña no es diferente en principio, salvo que los talleres son inmuebles en tanto que dicho material ferroviario puede trasladarse de un lado a otro.

La solución santiaguina de la licitación de recorridos resuelve también el problema de la expansión, probablemente excesiva, del parque de vehículos que trae consigo la desreglamentación del transporte colectivo. La mejor opción involucraría el cobro a cada bus de un peaje que refleje los costos sociales de la congestión, la contaminación y los accidentes causados por su presencia en las calles. Sin embargo, mientras que no se adopte una tarificación vial correspondiente para los vehículos particulares, será inoportuno pensar en aplicarla al transporte colectivo.

\footnotetext{
${ }^{1} \mathrm{Si}$ los usuarios son pocos y bien organizados, podrían llevar a
cabo investigaciones destinadas a comprobar la existencia de prác-

${ }^{1} \mathrm{Si}$ los usuarios son pocos y bien organizados, podrían llevar a
cabo investigaciones destinadas a comprobar la existencia de prácticas anticompetitivas que les perjudicaran. Sin embargo, los pasa-
jeros de autobuses son múltiples y no suelen estar organizados, ticas anticompetitivas que les perjudicaran. Sin embargo, los pasa-
jeros de autobuses son múltiples y no suelen estar organizados, aunque en varios países se han constituido recientemente instituciones dedicadas a la defensa de los intereses de los consumidores.
} 


\section{Bibliografía}

Argentina, Ministerio de Economía y Obras y Servicios Públicos (1972): Estudio preliminar del transporte de la región metropolitana, Buenos Aires.

(1977): Plan Nacional de Transporte. Antecedentes históricos 1965-1977, vol. 1, Buenos Aires.

Argentina, Secretaría de Obras Públicas y Transporte (1996): Compendio estadístico del transporte en la Argentina, Buenos Aires.

Bly, P., F. Webster y S. Pounds (1980): Subsidisation of Urban Public Transport, informe SR.541, Crowthorne, Reino Unido, Transport and Road Research Laboratory.

Button, K. (1990): Transport regulation in advanced capitalist nations: The case of USA, Deregulation and Transport, Londres, David Fulton Publishers.

CEPAL (Comisión Económica para América Latina y el Caribe (1987): Transporte interurbano de pasajeros en Chile: informe principal, LC/R.520-Rev.1, Santiago de Chile.

(1991): El transporte interurbano por bus en Argentina, Brasil y Chile: un análisis comparativo, LC/G.1662, Santiago de Chile, junio.

(1992): El efecto de los subsidios, la reglamentación y jas diversas formas de propiedad en la calidad y eficiencia operativa de los servicios del transporte urbano en América Latina, LC/L.675, Santiago de Chile.

(1994): El desarrollo del transporte público urbano en América Latina y el mundo, LC/G.1817, Santiago de Chile.

CIDATT (Centro de Investigación, Documentación y Asesoría de! Transporte Terrestre) (1997): El servicio público de transporte interprovincial de pasajeros por carretera en ómnibus, $B i$ blioteca de transporte, vol. 7, Lima.

Dyos, H. y D. Alderoft (1969): British Transport: An Economic Survey from the Seventeenth Century to the Twentieth, Harmondsworth, Reino Unido, Penguin Books.

Glover, J. (1996): National Railways: A Guide to the Privatised Railway, Shepperton, Reino Unido, Ian Allan Publishing,

González Narváez, C. (1992): La desregulación del autotransporte federal en México y sus perspectivas, Autoridad de control en el sector transporte, Buenos Aires, Ministerio de Economía y Obras y Servicios Públicos.
International Railway Journal (varios años): Bristol, Connecticut.

Jane's World Railways (varios años): Surrey, Canadá, Jane's Information Group Limited.

Jaramillo, S. y A. Parías (1995): Vida, pasión y muerte del tranvía en Bogotá, documento CEDE $\mathrm{N}^{\circ}$ 3, Santafé de Bogotá, Universidad de Los Andes, Centro de Estudios sobre Desarrollo Económico (CEDE).

Powell, T. (1992): Tendencias internacionales en la privatización y desregulación del transporte: experiencias de nuevas autoridades de control, Seminario sobre Autoridad de Control en el Sector Transporte, Buenos Aires, Ministerio de Economía y Obras y Servicios Públicos/GTZ alemán, junio.

Realidad Ferroviaria (varios años): Buenos Aires, Fundación Instituto Argentino de Ferrocarriles.

Rieles (varios años): Buenos Aires, Magazine Satelital, S.R.L.

Scobie, J. (1977): Buenos Aires: Del centro a los barrios, 1870-1910, Buenos Aires, Solar/Hachette,

Thomson, 1.(1992): Urban bus deregulation in Chile, Journal of Transpon Economics and Policy, vol. 26, $\mathrm{N}^{\circ} 3$, Londres, London School of Economics and Political Science.

(1993): La desreglamentación del transporte autobusero urbano e interurbano: Cómo funciona y cómo podría funcionar mejor, Memoria del VI Congreso Latinoamericano de Transporte Público (CLATP) y del VI Encuentro Latinamericano de Transporte Urbano (ELATU), San José de Costa Rica, FUNDESTRA.

(1994): The transportation systems of Latín American cities: How they might better serve the needs of the poor, Enhancing the Management of Metropolitan Living Environments, in Latin America, UNCRD-Research report series, $\mathrm{N}^{\circ}$ 1, Nagoya, Japón, Centro de las Naciones Unidas para el Desarrollo Regional.

. (1995): Una evaluación crítica de algunos aspectos de! desarrollo del sistema de transporte urbano de Santiago, F. Martínez Concha (ed.), Actas de VII Congreso Chileno de Ingeniería de Transporte, Santiago de Chile, Sociedad Chilena de Ingeniería de Transporte (SOCHITRAN).

Transportation Quarterly (1985): Joint Conference, Eno Foundation, Board of Directors and Board of Consultants, Westport, Connecticut, abril. 